\title{
Crowdsourcing geographic information for disaster management and improving urban resilience: an overview of recent developments and lessons learned
}

\author{
João Porto de Albuquerque ${ }^{\star, \dagger}$, Melanie Eckle ${ }^{\dagger}$, \\ Benjamin Herfort ${ }^{\dagger}$ and Alexander Zipf ${ }^{\dagger}$ \\ ${ }^{*}$ Centre for Interdisciplinary Methodologies, University of Warwick, UK, \\ j.porto@warwick.ac.uk, joao.porto@geog.uni-heidelberg.de \\ ${ }^{\dagger}$ GIScience Chair, Heidelberg University, Germany
}

\begin{abstract}
In the past few years, crowdsourced geographic information (also called volunteered geographic information) has emerged as a promising information source for improving urban resilience by managing risks and coping with the consequences of disasters triggered by natural hazards. This chapter presents a typology of sources and usages of crowdsourced geographic information for disaster management, as well as summarises recent research results and present lessons learned for future research and practice in this field.
\end{abstract}

\section{Keywords}

Crowdsourced Geographic Information, Volunteered Geographic Information, Disaster Management, Social Media, OpenStreetMap

How to cite this book chapter:

de Albuquerque, J P, Eckle, M, Herfort, B and Zipf, A. 2016. Crowdsourcing geographic information for disaster management and improving urban resilience: an overview of recent developments and lessons learned. In: Capineri, C, Haklay, M, Huang, H, Antoniou, V, Kettunen, J, Ostermann, F and Purves, R. (eds.) European Handbook of Crowdsourced Geographic Information, Pp. 309-321. London: Ubiquity Press. DOI: http://dx.doi.org/10.5334/bax.w. License: CC-BY 4.0. 


\section{Introduction}

The potential of Crowdsourced Geographic Information (CGI) as a new information source for disaster risk management has been paradigmatically shown during the earthquake that hit Haiti in 2010. Due to a lack of official data, information gathered from social media, via SMS and from OpenStreetMap became crucial for disaster response. In the past few years, CGI found their way into different disaster situations and scenarios (Horita et al. 2013). The use of geographic information for disaster risk management has attracted great interest both in research and practice, mainly because of the possibility to tap into the 'collective intelligence' or the 'wisdom of the crowds' to improve urban resilience, i.e. to improve the capacity of urban areas to better managing disaster risks and coping with the effects of extreme events.

In general, CGI in the context of disaster risk management can be categorised according to the information source into the following types:

1) Social media: Information produced by people about the event in usual social media platforms (e.g. Twitter, Flickr, Instagram, Facebook), such as from eyewitness that exchange and disseminate information about a disaster event.

2) Crowd sensing: Information collected from dedicated applications and platforms (e.g. Ushahidi) that are aimed specifically at producing information for disaster risk management.

3) Collaborative mapping: Information about geographic features of disasteraffected or disaster-prone areas, which is produced by volunteers using mapping platforms (e.g. OpenStreetMap, Wikimapia), e.g. as derived from satellite imagery.

Although there is a growing body of research related to each of these CGI types in different phases and tasks of disaster management, existing research studies usually focus on a particular type of CGI and are not able to relate to relevant developments associated with other CGI types. The goal of this chapter is to present to a holistic view of this field by means of a typology that is able to distinguish the main features and potentials of each CGI type for disaster risk management. This typology is valuable not only to summarise recent research results, but also to identify more integrated directions for future research on CGI towards improving disaster management and urban resilience. The next sections are thus dedicated to exploring these issues for each of the aforementioned CGI types in turn, followed by a conclusion.

\section{Social Media}

The first type of geo-information produced by the 'crowd' in the context of disasters is related to the use of existing social media platforms to exchange 
information. Social media has been defined as 'a group of Internet-based applications that build on the ideological and technological foundations of Web 2.0, and that allow the creation and exchange of User Generated Content' (Kaplan \& Haenlein 2010). As such, these platforms allow users to easily share self-produced content within a network of contacts and/or for the general public in a variety of forms: texts via blogs (from 'web log') or short messages in 'microblogging' (e.g. Twitter), web pages and forums, photos, videos, etc. Popular social media platforms include Twitter, Facebook, Flickr, YouTube, Instagram etc.

As people are increasingly familiar with and ordinarily use social media in their day-to-day life, they naturally tend to uptake these platforms in the occurrence of a disaster for communicating their experience and/or urgent needs. Indeed, in different catastrophic events of the past few years - from the wildfires in Southern California, USA in 2007, over the Earthquake in Haiti in 2010, up to the recent super typhoon in the Philippines 2013 - social media has enabled the affected population to produce information about extreme events and their catastrophic impacts (Sakaki, Okazaki \& Matsuo 2010; Crooks et al. 2013; De Longueville et al. 2010).

In the field of disaster risk management, a large part of the existing research focused on the analysis of short messages of the Twitter platform, the so-called Tweets (Steiger et al. 2015). For instance, Sakaki et al. (2010) and Crooks et al. (2013) investigated the use of Twitter for detecting and estimating the trajectory of earthquakes in real time. De Longueville et al. (2010) proposed the use of VGI as a sensor for detecting forest fire hot spots, based on previous work that analysed the application of Twitter as a source of spatiotemporal information for wildfire events in France. In contrast, Fuchs et al. (2013) showed that event detection based on peaks of Twitter activity did not work for the 2013 floods in Germany and presented an analysis of spatiotemporal clusters. Bakillah et al. (2014) applied graph clustering to support the detection of geolocated communities in Twitter after the typhoon Haiyan in the Philippines. Furthermore, a number of studies are concerned about developing tools for visualising social media data in order to enable make-sensing and location- based knowledge discovery (MacEachren et al. 2011; Terpstra \& de Vries 2012; Croitoru et al. 2013; Spinsanti \& Ostermann 2013).

Another group of studies seek to identify useful information from social media that could be valuable for improving situation awareness (Yin et al. 2012). For instance, Vieweg et al. (2010) and Starbird et al. (2010) analysed Twitter messages during the flooding of the Red River Valley in the United States and Canada in 2009, seeking to discern activity patterns and extract useful information.

Most of the existing work in the area has sought to make sense of social media data as a stand-alone source by analysing aggregated patterns, e.g. by defining thresholds for the size of spatiotemporal clusters of messages that would serve as signals for crisis events of earthquakes (Sakaki et al. 2010, Crooks et al. 2013), 
wildfires (De Longueville et al. 2010, Slavkovikj et al. 2014) or disease surveillance (Gomide et al. 2011, Bernardo et al. 2013). However, with such an approach the actual content of social media messages is largely ignored, and with this, much of their potential to improve the current knowledge about the unfolding situation is lost. Furthermore, although event detection is useful for sudden-onset crises for which there do not exist any other related data, in many concrete cases, there are additional information sources available. As pointed out by Lazer et al. (2014), one should not see 'big data' as a substitute for all existing data, but rather take the challenge of doing innovative analytics by using data from all traditional and new sources.

This is in line with a nascent research stream that uses VGI in combination with other geodata sources in the field of disaster management (Albuquerque et al. 2015; Schnebele, Cervone \& Waters 2014; Triglav-Čekada \& Radovan 2013; Spinsanti \& Ostermann 2013). For instance, Albuquerque et al. (2015) leveraged authoritative sensor data of water gauges to show that Tweets close to flooded areas are more probable to contain useful information for disaster management (see Figure 1).

Building upon these initial results, an important direction for future research endeavours is the development of improved analytical methods that are able leverage several different data sources in order to provide event detection, visualisation and information extraction from crowdsourced geo-information of social media that are better matched to the needs of decision makers in the field of disaster management.

\section{Crowd Sensing}

A second type of activity related to the use of new collaborative technologies for disasters is the emergence of the so-called 'crowd sensing' (Ma et al. 2014). This activity involves citizens on the Web that can act as sensors and share their observations. Differently from crowdsourced information derived from social media covered in the previous section, here the term 'crowd sensing' is used to describe approaches that rely upon dedicated software platforms for gathering specific and structured data, as well as for exploiting the interpretive and analytic skills and local knowledge of citizens.

These approaches are also related to the concept of citizen science, which is described by Haklay (2013) as 'scientific activities in which non-professional scientists voluntarily participate in data collection, analysis and dissemination of a scientific project'. As such, people using platforms for 'citizens as sensors' or 'citizen scientists' get engaged for accomplishing a set of tasks in a coordinated and purposeful manner. These tasks mostly involve some kind of data collection for different types of scientific investigations, the most famous examples being bird watching and other types of environmental observations. 


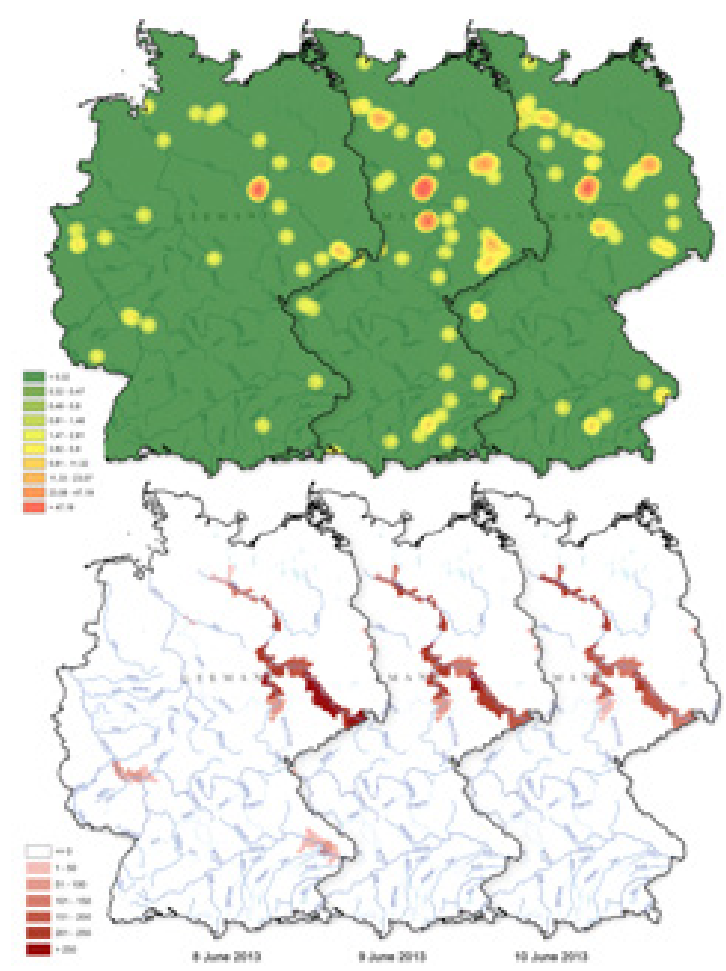

Figure 1: Distribution of Twitter messages that were sent during the 2013 Elbe Floods in Germany (top) in contrast with flooded catchments as indicated by river gauges (bottom) (adapted from de Albuquerque et al. 2015).

In the context of disasters, several 'crowd sensing' platforms were created including dedicated mobile applications for disaster management and earth observation (Ferster \& Coops 2013). Using volunteers to perform a specific task, such as environmental monitoring, collectively make a Citizen Observatory (CO), where data can be collected, collated and published (Degrossi, et al. 2014; Liu et al. 2015). Thus, the term Citizen Observatory can be understood as a software platform used by citizens to produce volunteered information about a specific topic through different devices (e.g. web, mobile app and SMS), and allow their visualisation.

An important software platform for implementing Citizen Observatories is called Ushahidi' (which means 'testimony' in Swahili). This platform was first developed in the context of election monitoring in Kenya and later developed

${ }^{1}$ Available at: http://www.ushahidi.com [Accessed February 12 $2^{\text {th }} 2014$ ]. 


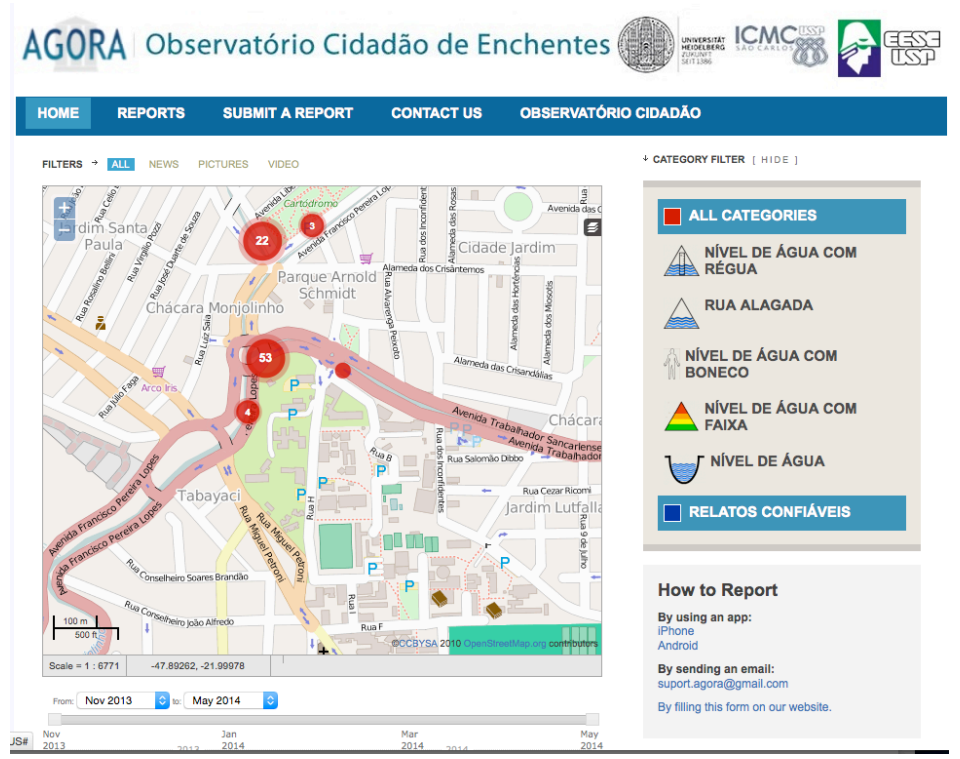

Figure 2: Flood Citizen Observatory prototype (adapted from Degrossi et al. 2014).

as an open-source toolbox that can be deployed in several situations to collect data from on-the-ground volunteers via web site and mobile application, but also for remote volunteers to collaborative categorise information collated from many sources, including social media (discussed in the previous section). One application example that is built upon the Ushahidi platform is the prototype Flood Citizen Observatory implemented in Brazil (Figure 2) for allowing citizens to report about the local conditions of river levels, flooded areas, as well as consequences of flooding (Degrossi et al. 2014; Horita et al. 2015).

While crowd sensing and citizen observatories can be potentially used to provide useful information about the impacts caused by extreme events and their victims, one important issue is to be addressed is how to motivate people to contribute with valuable information. Another important point to be addressed is how to validate and integrate information from volunteers with other sources of data for effectively improving decision-making related to disaster risk management.

\section{Collaborative Mapping}

The third type of crowdsourced geo-information comprises a specific type of information and collaboration platform: the collaborative edition of geographic 
features to fulfil internet-based interactive maps. The well-known platforms Wikimapia ${ }^{2}$ and OpenStreetMap (OSM) ${ }^{3}$ fall into this category, as well as the 'crowdsourcing' component of the popular GoogleMaps platform, so-called GoogleMapMaker ${ }^{4}$ (which, unlike the previous ones, does not have an open data policy and thus does not provide users with full access to the collected data).

A distinctive feature of this type of activity is the collaborative collection of a very specific type of data - namely, georeferenced data about features like streets and roads, buildings etc. - and the structuring of this information in form of a map. In doing so, the volunteer community seeks to produce a map that is as complete and detailed as possible, leveraging the local knowledge of a wide base of users to collaboratively fill the gaps. Recent research works have shown that, at least for the regions with the most active communities in OSM, the results achieved a quality level that is comparable to official and commercial maps (Neis, Zielstra \& Zipf 2011; Haklay 2010).

The maps produced by volunteers in this way are clearly of great relevance in the context of disasters. High quality and precise maps are an important resource for a number of tasks in disaster management, being used from emergency planning up to the coordination of relief efforts. In several disaster events of the past few years, the volunteer community has been very actively engaged in producing collaborative maps to assist disaster management, especially the community of OpenStreetMap. By digitising the infrastructure, and especially important, also the level of damage (where it can be detected), they create a situation map that can be used by the emergency responders directly in the field.

After the devastating earthquake that struck Haiti in January 2010, for instance, there was a very significant response of the international OSM community (Neis et al. 2010; Zook et al. 2010). In the aftermath of that severe quake, good-quality maps were not available to guide the relief efforts, and the standard map services in the web (e.g. GoogleMaps) lacked adequate coverage and had to be updated to reflect the current status of the many blocked roads and streets. A few hours after the quake, the volunteers of the OpenStreetMap (OSM) community around the world started mapping remotely the affected regions based on satellite imagery, seeking to trace the outlines of streets, buildings and places of interest. Later, high-resolution and very up-to-date post-disaster satellite images were made freely available and the OSM community could then resort to those in order to also record the damage of buildings and blockages in streets and roads. Such imagery is a very crucial source of information for the mappers to be used, because it allows also volunteers to contribute from all over the world, not only people that are directly at the affected areas. For large-scale disaster events with many international contributors this can

\footnotetext{
2 Available at: http://wikimapia.org [Accessed February 12 $2^{\text {th }} 2014$ ].

3 Available at: http://openstreetmap.org [Accessed February 12 ${ }^{\text {th }} 2014$ ].

${ }^{4}$ Available at: https://www.google.com/mapmaker [Accessed February 12 ${ }^{\text {th }}$ 2014].
} 


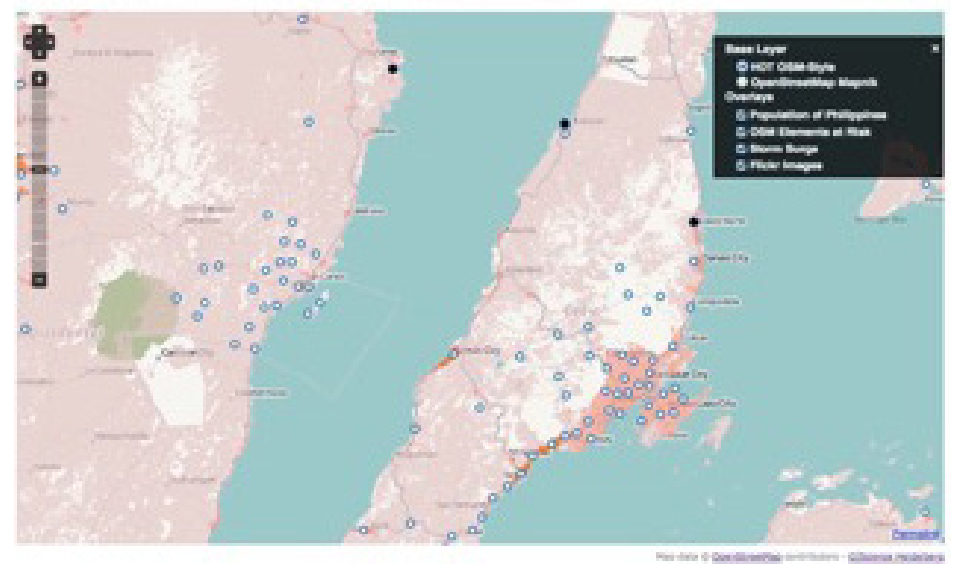

Figure 3: Elements of the critical infrastructure from OpenStreetMap in the Phillipines, which was affected by Typhoon Haiyan 2013 (adapted from Reimer et al. 2014).

generate highly-detailed maps extremely quickly. The information produced was then available for guiding relief efforts, not only allowing better visual orientation through the interactive maps, but also for importing the data into GPS devices for local orientation, as well as using the database behind OSM for providing more sophisticated services. For instance, an emergency routing service was developed to allow quick identification of the best routes for relief efforts based on the up-to-date situation mapped by the OSM community (Neis, Singler \& Zipf 2010).

Ever since 2010, numerous OSM contributors provided their support in mapping events in the aftermath of a disaster, producing the so-called Crisis Maps. As a result, within the OSM community a initiative called Humanitarian OpenStreetMap Team (H.O.T. $)^{5}$ was launched to organise the many crisis mapping actions of the OSM community and is also in contact with other relevant humanitarian organisations. This engagement attracted serious interest in academic circles as well as on the side of humanitarian-aid organisations (Harvard Humanitarian Initiative 2011; United Nations Office for the Coordination of Humanitarian Affairs 2013). One significant example of the use of such information could be attested in a more recent major catastrophic event: the typhoon Haiyan that hit the Philippines in 2013 (Reimer et al. 2014). In this case, the international OSM community was also very active and collaborated in a coordinated way with humanitarian organisations such as the American

${ }^{5}$ Available at: http://hot.openstreetmap.org/ [Accessed February 12 ${ }^{\text {th }} 2014$ ]. 
Red Cross and UN-OCHA (Office for Coordination Affairs of the United Nations), for example, for extracting information about elements at risk of the so-called Critical Infrastructure (see Figure 3), i.e. critical elements that must particular attention in a disaster management such as schools, hospitals, fuel stations etc. (Reimer et al. 2014; Schelhorn et al. 2014; Herfort et al. 2015).

However, while one main advantage of OSM is that their contributors mainly focus on their well-known local surroundings (Goodchild 2007; Neis \& Zipf 2012), Crisis Maps originate largely from mappers who work remotely. Therefore, due to the fact that OSM is a crowdsourced map and that a main part of the data in Crisis Maps originates exclusively from contributors that work remotely, humanitarian-aid agencies and first responders have doubts about the quality of the OSM data and therefore sometimes refrain from utilising it (Harvard Humanitarian Initiative 2011). Furthermore, activity areas of remote mappers generally lack official cross-reference data, making it difficult to apply usual quality assessment methods, which are based on comparisons with reference data. In this manner, an important direction for future research is to develop methods for assessing and improving the quality of the geo-information produced by remote volunteers, especially considering the particular needs and requirements of the field of disaster risk management.

\section{Conclusion}

Crowdsourced geographic information (CGI) holds a big potential not only for coping with the effects of disaster events, but also for implementing preventive measures for improving the resilience of urban areas against natural hazards and extreme events. We presented and discussed three main types of crowdsourced geo-information that can be explored for this purpose: social media, crowd sensing and collaborative maps.

CGI of these different types can be incorporated into disaster risk management in many different ways. As shown in the previous sections, the most important usage of CGI in this context is improve situation awareness in the monitoring of unfolding events, i.e. to complement conventional information sources with first-hand geographic information from the crowd shared in social media, citizen sensing platforms and/or collaborative maps. In this manner, it is possible to get more fine-grained and up-to-date spatial information about what is happening on the ground. Clearly, this information is of great value for creating maps to support emergency agencies in disaster relief, both in field missions and in emergency operation centres. Although CGI is becoming more and more used for this purpose, significant challenges remain in filtering and prioritising useful and valuable information amidst the large stream of non-relevant data. Since most existing studies are still focused on a single source of CGI, the integration and fusion of the different types of CGI 
with other authoritative data sources and processes of emergency agencies is a still underexplored topic that should be addressed in future research efforts in this area.

Furthermore, the use of CGI in mitigation and preparation phases should be emphasised in future studies. This could be done for instance by leveraging initial examples of using CGI from collaborative maps to support activities in disaster risk management, such as in the identification of critical infrastructures to support emergency planning (Herfort et al. 2015; Schelhorn et al. 2014), for instance for performing evacuation simulations (Bakillah et al. 2012, Goetz \& Zipf 2012) and estimating the vulnerability of urban areas based on synthetic information about the potentially affected population (Bakillah et al. 2014).

\section{References}

de Albuquerque, J. P., Herfort, B., Brenning, A., \& Zipf. A. 2015. A Geographic Approach for Combining Social Media and Authoritative Data towards Identifying Useful Information for Disaster Management. International Journal of Geographical Information Science: 1-23. Available at: http://www.tandfonline. com/doi/abs/10.1080/13658816.2014.996567.DOI:http://dx.doi.org/10.1080/ 13658816.2014.996567

Bakillah, M., Andrés Domínguez, J., \& Zipf, A. 2012. Multi-agents Evacuation Simulation Data Model with Social Considerations for Disaster Management Context. The 8th International Conference for Geo-Information for Disaster Management. GI4DM. Enschede. The Netherlands.

Bakillah, M., Liang, S., Mobasheri, A., Arsanjani, J. J., \& Zipf, A. 2014. FineResolution Population Mapping Using OpenStreetMap Points-of-Interest. International Journal of Geographical Information Science, (April 24): 1-24. Available at: http://www.tandfonline.com/doi/abs/10.1080/13658816.2014. 909045. DOI: http://dx.doi.org/10.1080/13658816.2014.909045

Crooks, A., Croitoru, A., Stefanidis, A., \& Radzikowski, J. 2013. “\#Earthquake: Twitter as a Distributed Sensor System.” Transactions in GIS, 17(1): 124147. Available at: http://doi.wiley.com/10.1111/j.1467-9671.2012.01359.x. DOI: http://dx.doi.org/10.1111/j.1467-9671.2012.01359.x

De Longueville, B., Annoni, A., Schade, S., Ostlaender, N., \& Whitmore, C. 2010. DigitalEarth'sNervousSystemforCrisisEvents:Real-TimeSensorWebEnablement of Volunteered Geographic Information. International Journal of Digital Earth, 3(3) (September): 242-259. Available at: http://www.tandfonline.com/ doi/abs/10.1080/17538947.2010.484869. DOI: http://dx.doi.org/10.1080/ 17538947.2010 .484869

Degrossi, L. C., Albuquerque, J. P., Fava, M. C., \& Mendiondo, E. M. 2014. Flood Citizen Observatory: A Crowdsourcing-Based Approach for Flood Risk Management in Brazil. In: 26th International Conference on Software Engineering and Knowledge Engineering (SEKE 2014). 
Ferster, C. J., \& Coops, N. C. 2013. A Review of Earth Observation Using Mobile Personal Communication Devices. Computers \& Geosciences, 51: 339-349. Available at: http://www.sciencedirect.com/science/article/pii/ S0098300412003184.

Goetz, M., \& Zipf, A. 2012. Using Crowdsourced Indoor Geodata for AgentBased Indoor Evacuation Simulations. ISPRS International Journal of Geo-Information, 1(2): 186-208. MDPI. DOI: http://dx.doi.org/10.3390/ ijgi1020186

Goodchild, M. F. 2007. Citizens as Sensors: The World of Volunteered Geography. GeoJournal, 69(4): 211-221.

Haklay, M. 2013. Citizen Science and Volunteered Geographic Information: Overview and Typology of Participation. In: Sui, D., Elwood, S., \& Goodchild, M. (Eds.) Crowdsourcing Geographic Knowledge. Dordrecht: Springer Netherlands, pp. 105-122. Available at: http://www.springerlink.com/ index/10.1007/978-94-007-4587-2. DOI: http://dx.doi.org/10.1007/97894-007-4587-2.

Haklay, M. 2010. How Good Is Volunteered Geographical Information? A Comparative Study of OpenStreetMap and Ordnance Survey Datasets. Environment and Planning B: Planning and Design, 37(4): 682-703. Available at: http://discovery.ucl.ac.uk/150445/.

Harvard Humanitarian Initiative. 2011. Disaster Relief 2.0. Washington D.C., Berkshire.

Herfort, B., Eckle, M., Albuquerque, J. P., \& Zipf, A. 2015. Towards Assessing the Quality of Volunteered Geographic Information from OpenStreetMap for Identifying Critical Infrastructures. In: Proceedings of the ISCRAM 2015 Conference - Kristiansand, May 24-27, edited by Palen, Büscher, Comes, and Hughes. Kristiansand, Norway, pp. 1-8.

Horita, F. E. A., Degrossi, L. C., Assis, L. F. F. G., Zipf, A., \& Albuquerque, J. P. 2013. The Use of Volunteered Geographic Information and Crowdsourcing in Disaster Management: A Systematic Literature Review. In: Proceedings of the Nineteenth Americas Conference on Information Systems, Chicago Illinois, August 15-17, 2013. Atlanta, GA, USA: AIS, pp. 1-10.

Horita, F. E. A., Albuquerque, J. P., Degrossi, L. C., Mendiondo, E. M., \& Ueyama, J. 2015. Development of a Spatial Decision Support System for Flood Risk Management in Brazil That Combines Volunteered Geographic Information with Wireless Sensor Networks. Computers \& Geosciences, 80: 84-94. Available at: http://www.sciencedirect.com/science/article/pii/ S0098300415000746. DOI: http://dx.doi.org/10.1016/j.cageo.2015.04.001

Kaplan, A. M., \& Haenlein, M. 2010. Users of the World, Unite! The Challenges and Opportunities of Social Media. Business Horizons, 53(1): 59-68. Available at: http://ideas.repec.org/a/eee/bushor/v53y2010i1p59-68.html.

Liu, H-Y., Kobernus, M., Broday, D., \& Bartonova, A. 2015. A Conceptual Approach to a Citizens' Observatory - Supporting Community-Based Environmental Governance. Environmental Health: A Global Access Science 
Source, 14(1): 107. Available at: http://www.ehjournal.net/content/13/1/107. DOI: http://dx.doi.org/10.1186/1476-069X-13-107

Ma, H., Zhao, D., \& Yuan, P. (2014). Opportunities in mobile crowd sensing. IEEE Communications Magazine, 52(8), 29-35. http://doi.org/10.1109/ MCOM.2014.6871666

Neis, P., Singler, P., \& Zipf, A. 2010. Collaborative Mapping and Emergency Routing for Disaster Logistics - Case Studies from the Haiti Earthquake and the UN Portal for Afrika. In: Geospatial Crossroads @ GI_Forum 2010. Proceedings of the Geoinformatics Forum Salzburg. Salzburg, Austria, pp. 239-248.

Neis, P., Zielstra, D., \& Zipf, A. 2011. The Street Network Evolution of Crowdsourced Maps: OpenStreetMap in Germany 2007-2011. Future Internet, 4(1): 1-21. DOI: http://dx.doi.org/10.3390/fi4010001. Available at: http:// www.mdpi.com/1999-5903/4/1/1/

Neis, P., \& Zipf, A. 2012. Analyzing the Contributor Activity of a Volunteered Geographic Information Project - The Case of OpenStreetMap. ISPRS International Journal of Geo-Information, 1(2): 146-165. Available at: http://www.mdpi. com/2220-9964/1/2/146/htm. DOI: http://dx.doi.org/10.3390/ijgi1020146

Reimer, A., Neis, P., Rylov, M., Schellhorn, A., Sagl, G., Resch, B., Albuquerque, J.P., \& Zipf, A. 2014. Erfahrungsbericht Crisis Mapping Zum Taifun Hayan. In: Gemeinsame Jahrestagung, Geoinformatik 2014. Hamburg.

Sakaki, T., Okazaki, M., \& Matsuo, Y. 2010. Earthquake Shakes Twitter Users. In: Proceedings of the 19th International Conference on World Wide Web - WWW'10, 851. New York, New York, USA: ACM Press. Available at: http://dl.acm.org/citation.cfm?id=1772690.1772777. DOI: http://dx.doi. org/10.1145/1772690.1772777

Schelhorn, S. J., Herfort, B., Leiner, R., Zipf, A., \& Albuquerque, J. P. 2014. Identifying Elements at Risk from OpenStreetMap: The Case of Flooding. In: Hiltz, S. R., Pfaff, M. S., Plotnick, L., \& Shih, P. C. (Eds.) Proceedings of the 11th International ISCRAM Conference. University Park, Pennsylvania, USA,: ISCRAM, pp. 508-512.

Schnebele, E., Cervone, G., \& Waters, N. 2014. Road Assessment after Flood Events Using Non-Authoritative Data. Natural Hazards and Earth System Science, 14(4): 1007-1015. Available at: http://www.nat-hazards-earthsyst-sci.net/14/1007/2014/nhess-14-1007-2014.html. DOI: http://dx.doi. org/10.5194/nhess-14-1007-2014

Spinsanti, L., \& Ostermann, F. 2013. Automated Geographic Context Analysis for Volunteered Information. Applied Geography, 43: 36-44. DOI: http:// dx.doi.org/10.1016/j.apgeog.2013.05.005

Steiger, E., Albuquerque, J. P., \& Zipf, A. 2015. Twitter as a Location Based Social Network - An Advanced Systematic Literature Review on Spatiotemporal Analyses of Twitter Data. Transactions in GIS. DOI: http://dx.doi. org/10.1111/tgis.12132

Triglav-Čekada, M., and D. Radovan. 2013. "Using Volunteered Geographical Information to Map the November 2012 Floods in Slovenia." Natural 
Hazards and Earth System Science, 13(11) (November 5): 2753-2762. Available at: http://www.nat-hazards-earth-syst-sci.net/13/2753/2013/nhess-132753-2013.html. DOI: http://dx.doi.org/10.5194/nhess-13-2753-2013

UN OCHA. 2012. Humanitarianism in the Network Age.

Zook, M., Graham, M., Shelton, T., \& Gorman, S. 2010. "Volunteered Geographic Information and Crowdsourcing Disaster Relief: A Case Study of the Haitian Earthquake." World Medical \& Health Policy, 2(2) (July 21): 7. Available at: http://www.psocommons.org/wmhp/vol2/iss2/art2. DOI: http://dx.doi.org/10.2202/1948-4682.1069 